\title{
O trato com o conhecimento da dança na escola Trabalho pedagógico na formação do professor na Bahia
}

\author{
Josiane Cristina Climaco* \\ Claudio de Lira Santos Junior \\ Celí Nelza Zulke Taffarel ${ }^{* * *}$
}

\begin{abstract}
RESUMO: As dificuldades para inserir e contextualizar de forma sistematizada a dança no currículo da Educação Física na escola, inspíraram esta pesquisa, em que buscamos desenvolver o trato deste conhecimento e especificar que se trata de um conhecimento e de um conteúdo específico da cultura corporal a ser contemplado na escola, e cujo sentido ontológico é formar o ser social.
\end{abstract}

Palavras-chave: Dança. Educação Física. Currículo Escolar.

\section{Using the knowledge of dance in school: \\ Pedagogical work in teacher formation in Bahia}

\begin{abstract}
This research is inspired by the difficulties to insert and systematize dance into the Physical Education curriculum in schools. We seek to develop and use this knowledge and to specify that it is knowledge of and a specific content of the corporal culture to be contemplated in school, and whose ontological sense is to form the social being.
\end{abstract}

Keywords: Dance. Physical education. School curriculum.

* Doutoranda em Educação na Universidade Federal da Bahia. É mestre em Educação pela mesma instituição. Atualmente atua como professora na Secretaria de Educação do Estado da Bahia. Salvador, BA- Brasil. E-mail: <jcclimaco@gmail.com>.

** É mestrado em Educação pela Universidade Federal de Pernambuco e doutor em Educação pela Universidade Federal da Bahia. Atualmente é professor associado da Universidade Federal da Bahia. Salvador, BA- Brasil. E-mail: <clirasjr@gmail.com>.

*** É mestre em Ciência do Movimento Humano pela Universidade Federal de Santa Maria, e doutora em Educação pela Universidade Estadual de Campinas. Atualmente é professora titular da Universidade Federal da Bahia. Salvador, BA- Brasil. E-mail:<taffarel@ufba.br>. 


\section{La relación con el conocimiento de la danza en la escuela Trabajo pedagógico en la formación del profesor en Bahia}

RESUMEN: Las dificultades en la introducción y contextualización sistematizadas de la danza en el programa docente de Educación Física en la escuela inspiraron este estudio, en el que buscamos desarrollar el tratamiento de este conocimiento y especificar que se trata de un conocimiento y de un contenido específico de la cultura corporal a contemplar en la escuela, y cuyo sentido ontológico es formar el ser social.

Palabras clave: Danza. Educación Física. Currículo Escolar.

\section{La question de la connaissance de la danse à l'école: Travail pédagogique en formation de professeur à Bahia}

RÉSUMÉ: Ce sont les difficulés à insérer et contextualiser de forme systématique la danse dans le programme d'Éducation Physique à l'école qui ont inspiré cette recherche, dans laquelle nous cherchons à analyser le traitement reçu par cette forme de connaissance et à montrer qu'il s'agit d'un savoir et d'un contenu spécifique de la culture corporelle qui doivent être pensés au sein de l'école et dont le sens ontologique est la formation de l'être social.

Mots-clés: Danse. Éducation Physique. Programme Scolaire.

\section{Introdução}

$\mathrm{E}$ studos de outros autores e pesquisas sobre a dança na escola apresentam relatos e entrevistas de professores (as) sobre a ausência do trato deste conhecimento na escola de forma sistematizada. Segundo Brasileiro (2003) a dança é minimamente tratada como folclore nas escolas. Raramente é valorizada. É reconhecida como atividade extraescolar e extracurricular.

No ensino da dança, ainda segundo Brasileiro (2003), se faz necessário discutir, no interior da escola, que ela contribui para uma dada concepção de ser humano e de mundo, que é refletida nos projetos científicos, políticos, pedagógicos, éticos e estéticos. A dança é um conhecimento e conteúdo específico da cultura corporal que deve ser contemplado na escola. 
Para além da autora e outros estudos, como supervisora do Programa Institucional de bolsas e iniciação à docência- Pibid Educação Física, na Universidade Federal da Bahia (UFBA), constatamos em nosso subprojeto, e também nas aulas de professores (as) de Educação Física (EF) da educação básica da Rede Estadual da Bahia, as dificuldades encontradas para inserir e contextualizar de forma sistematizada a dança no currículo da Educação Física na escola.

A dança enquanto um conhecimento selecionado pelos professores de EF para o trato pedagógico continua ausente; eles apontam como entraves o preconceito, a intolerância religiosa, as problemáticas sobre questões de gênero, a resistência dos estudantes a determinados estilos, visando priorizar a dança na perspectiva do senso comum, e o tempo pedagógico.

Porém, instiga-nos a desenvolve-lo, para não decorrermos no erro da negação do conhecimento, entendendo que os entraves fazem parte de nossa sociedade e a escola é parte da sociedade, o que nos qualifica para enfrentar tais problemáticas, considerando, de acordo com Saviani (2008), que a escola tem como função principal a emancipação humana.

Todavia, para desenvolver o trato deste conhecimento buscamos saber: (a) gênese da atividade específica da dança; (b) historicidade da dança; (c) atividades principais para a aprendizagem e; (d) a organização do conhecimento nos ciclos de ensino e aprendizagem. Estas categorias nos dão condições de estabelecer generalizações sobre como ensinar a dança na escola visando atender aos princípios específicos sobre como se dá o trato com o conhecimento da Educação Física (TCCEF). Para Taffarel e Escobar, discorrendo em estudos e elaborando este conceito no livro Metodologia do ensino de Educação Física, conhecido como Coletivo de autores (2009), retrata que o TCCEF estabelece princípios curriculares que orientam o trabalho educativo.

O Coletivo de Autores (2009) apresenta o debate da dinâmica curricular entre a lógica formal e a lógica dialética. Segundo os autores, a lógica formal não possibilita a apreensão do conhecimento, pois este apresenta como característica principal o conhecimento inculcado que leva à formação do ser humano de forma isolada. Assim, nos apresenta como proposição a dinâmica curricular dialética:

[...] dinâmica curricular na perspectiva dialética favorece a formação do sujeito histórico à medida que lhe permite construir, por aproximações sucessivas, novas e diferentes referências sobre o real no seu pensamento. Permite-lhe, portanto, compreender como o conhecimento foi produzido historicamente pela humanidade e o seu papel na história dessa produção. (COLETIVO DE AUTORES, 2009, p.35)

Desta forma, ao dialogar com estes pressupostos, apresentamos como eles conceituam os princípios da seleção, organização e sistematização do conhecimento. Quanto à seleção dos conteúdos, 
[...] a relevância social atribuída ao conhecimento em questão para ser selecionado como conteúdo da disciplina e, portanto, a relação dele com o projeto histórico, com a realidade atual, com o projeto pedagógico da escola e com a necessidade de o aluno fazer a leitura da realidade. (ESCOBAR, 1997, p.87)

Já a organização do conhecimento

[...] ao longo das séries e/ou ciclos é dada pela forma em que a escola promove a assimilação do conhecimento nos escolares, forma resultante da vinculação de uma determinada teoria do conhecimento com uma determinada abordagem da psicologia cognitiva, que fundamenta a reflexão pedagógica no processo de escolarização, resultando na divisão do conteúdo das disciplinas para as diferentes séries, assim como incidindo sobre a determinação do tempo necessário para os alunos aprenderem, tendo em conta, ou não, suas condições individuais diferenciadas. (IDEM, p.88)

E, por fim, sobre a sistematização do conhecimento, a autora considera como indicadores os procedimentos com que o professor apresenta o assunto ou tema, e que possibilite nos estudantes a constatação dos elementos componentes do conceito, a interpretação dos significados, a compreensão de como este conhecimento tem relação com a vida e, finalmente, a explicação sobre o conhecimento em questão.

Portanto, para fundamentar o trato com o conhecimento da dança, buscamos a coerência entre os pressupostos teóricos metodológicos, que nos alicerçam num projeto histórico de sociedade para elevar o padrão cultural da classe trabalhadora que se encontra nas escolas públicas do País, em nosso caso em especial, na Bahia, onde estão os professores (as) e futuros professores(as) em formação. Que sejam hegemonicamente contra a alienação e a folclorização dos elementos da cultura corporal, que negligencia o conhecimento em âmbito escolar.

Portanto, o trato com o conhecimento da dança neste curso de formação continuada primou como fundamentação a teoria do conhecimento (Materialismo Histórico Dialético), a teoria pedagógica (Pedagogia Histórico-crítica) e da Metodologia do Ensino da Educação Física (Crítico-superadora).

\section{A dança e o trato com o conhecimento na escola}

Tomamos por base para explicar a seleção dos conteúdos a necessidade de apreender: a gênese da dança, sua historicidade e desenvolvimento nos diferentes modos de produção da humanidade e seus fundamentos, para estabelecer a relação com a organização do conhecimento.

\section{A dança e sua gênese}


A atividade humana tem sua gênese na necessidade da manutenção da vida. Para manter a sua vida o ser humano tem que produzir e reproduzir as condições de sua existência. Para manter-se em pé e poder fazer a história, portanto, é necessário ao ser humano trabalhar. É no trabalho humano que vamos encontrar a gênese de todas as atividades que, no decorrer do desenvolvimento histórico da humanidade adquirem diferentes sentidos e significados.

Os sentidos e significados das atividades humanas decorrem, portanto, das relações sociais estabelecidas em cada período do desenvolvimento da humanidade.

Na produção social da vida, os homens estabelecem relações determinadas, necessárias e independentes da sua vontade, relações de produção que correspondem a uma data fase de desenvolvimento das suas forças produtivas materiais. (MARX, 2004, p. 47).

Para explicar tal desenvolvimento, Leontiev sobre "O Homem e a Cultura" (2004, pp. 277-284):

\begin{abstract}
Mas então como é que a evolução dos homens se produziu? Qual o "mecanismo"? Pois, desde o princípio da história humana, os próprios homens e as suas condições de vida não deixaram de se modificar e as aquisições da evolução de se transmitir de geração em geração, o que era a condição necessária da continuidade do progresso histórico. Era preciso, portanto, que estas aquisições se fixassem. Mas como, se já vimos - elas não podem fixar-se sob o efeito da herança biológica? Foi sob uma forma absolutamente particular, forma que só aparece com a sociedade humana: a dos fenômenos externos da cultura material e intelectual. Esta forma particular de fixação e de transmissão às gerações seguintes das aquisições da evolução deve o seu aparecimento ao fato, diferentemente dos animais, de os homens terem uma atividade criadora e produtiva. É antes de mais o caso da atividade humana fundamental: 0 trabalho. Pela sua atividade, os homens não fazem senão adaptar-se à natureza. Eles modificam-na em função do desenvolvimento de suas necessidades. Criam os objetos que devem satisfazer as suas necessidades e igualmente os meios de produção desses objetos, dos instrumentos às máquinas mais complexas. Constroem habitações, produzem as suas roupas e outros bens materiais. Os progressos realizados na produção de bens materiais são acompanhados pelo desenvolvimento da cultura dos homens; o seu conhecimento do mundo circundante e deles mesmos enriquece-se, desenvolvem-se a ciência e a arte.
\end{abstract}

A dança é, portanto, uma atividade cuja gênese é o trabalho humano e que tem o sentido ontológico de formar o ser social. Atividade que vai sendo sistematizada pela humanidade e chega aos nossos dias com características que lhe são próprias e que decorrem do modo de produção da vida em cada período histórico.

Hoje a dança evidencia formas de expressão artística e pessoal. Estudá-la possibilita conhecer várias culturas, porque as formas de dançar de um povo revelam muitas coisas sobre seu modo de vida.

Dialogando com Marx (2004), se apropriando da categoria trabalho, podemos dizer que a dança não nasce por si e sim, em si; assim como todas as outras formas de 
expressões artísticas, ela vem da necessidade do homem externar contentamentos, frustrações, o modo de vida do seu povo, os costumes.

É uma atividade da cultura corporal, objeto de estudo da EF, como conceitua o Coletivo de autores, que se vale de códigos e símbolos aprendidos desde a mais tenra idade, vez que o ritmo faz parte das experiências humanas desde o ventre materno e se estende para as relações com a natureza, com os demais seres humanos ao longo da vida.

A dança é o movimentar-se através de ritmos mais elaborados que possibilitam uma variedade de tipos de danças, como: dança clássica, dança folclórica, dança de rua, entre muitas outras.

Os ritmos podem ser também imprimidos involuntariamente e voluntariamente, como por exemplo o ritmo cardíaco, até ritmos criados com o próprio corpo e com a utilização de materiais, instrumentos musicais. Segundo Zanella (2004),

Cultura é produto do trabalho, da atividade humana objetivada. Ao produzir a cultura, através da ação mediada, o homem, ao mesmo tempo, se objetiva e subjetiva, pois ao apropriar-se da atividade, o sujeito apropria-se da história humana e imprime a esta sua marca" (ZANELLA 2004, p.132).

O movimento de objetivação-subjetivação só é possível através da mediação de signos que necessitam ser aprendidos e, portanto, transmitidos/assimilados pelos seres humanos. Os signos são instrumentos produzidos pelos próprios homens e subjetivados por ele próprio. Esta é uma relação dialética, "na medida em que a atividade humana se processa, por seu intermédio, o sujeito se objetiva e transforma a realidade, ao mesmo tempo transforma a si mesmo e se subjetiva" (ZANELLA 2004, p. 132). Vai produzindo assim a cultura humana, em especial, a cultura corporal, particularmente a dança, objeto de nosso trato com o conhecimento como possibilidade neste capítulo.

\section{Gênese e historicidade em diferentes modos de produção}

A dança como expomos, em sua gênese, é produto do trabalho, ou seja, da atividade humana nas relações de produção da vida. Não se pode entender a dança à parte da história da humanidade. Ela vem da pré-história e é configurada quando, nas paredes de seu habitat, o homem registra os movimentos nas rochas e nas paredes das cavernas. Segundo Portinari (1989) "[...] estava diretamente relacionada à sobrevivência, no sentido de que os homens, vivendo em tribos isoladas e se alimentando de caça e pesca e de vegetais e frutos colhidos da natureza, criavam rituais em forma de dança que impediriam eventos naturais de prejudicar essas atividades".

No início da história humana, apresentava em seus movimentos a atividade vital do homem, estabelecendo o período das danças primitivas, de acordo com Rosana Van 
Langendonck (2006). Os homens criavam rituais, acreditando que, saudando a natureza, não haveria eventos naturais que prejudicassem a colheita, a caça e outros.

Em cavernas como as da Serra da Capivara, no Piauí, no Brasil, Fulton's Rock, na África do Sul, Altamira, na Espanha e Lascaux, na França podemos conhecer muitos desenhos dessas eras. Eles representam cenas de pessoas em roda, dançando em volta de animais e vestidas com suas peles; são figuras correndo e saltando, imitando as posturas e movimentos desses animais. (LANGENDONCK, 2006, p.3)

No Egito, Grécia e Índia, a dança era utilizada como exaltação aos deuses, integrada a rituais religiosos, antes das manifestações teatrais. Porém os gregos, em seu dançar, a usavam como entretenimento para a sociedade, sempre com a divisão de classes e também como parte do treinamento, para dar agilidade aos militares.

As danças milenares perpassaram todos os modos de produção. No modo de produção feudal, a partir da Idade Média, sob a influência da Igreja, a dança passa ser "demonizada", as manifestações corporais são proibidas, vinculadas ao pecado. Esse momento histórico, os humanistas do Renascimento denominaram Idade das Trevas, quando tudo era proibido; o teatro e a dança só eram permitidos quando fizessem alusão aos textos bíblicos e formalizados nos bailes das cortes.

No modo de produção escravocrata, a partir do século XV, com a mudança nas relações sociais de produção, a dança vai-se configurar pela cultura hegemônica, ou seja, a cultura dos colonizadores. Se analisarmos a constituição da sociedade brasileira e sua formação cultural, durante muitos anos a cultura indígena e a afro-brasileira foram negadas como conhecimento clássico, em registros como os livros didáticos, e se materializando nos currículos escolares em momentos pontuais, de forma folclorizada, colocando em evidência a cultura dominante. Diante deste contexto as danças se tornavam populares para a diversão da classe escravocrata e profana, aos excluídos.

Porém, na Europa, o trato da dança tem outra configuração:

O primeiro "balé da corte", intitulado Le Ballet Comique de la Reine (O Balé Cômico da Rainha - neste caso, o termo cômico deve ser entendido no sentido de "dramaturgia de uma comédia"), foi um grande espetáculo, que durou seis horas, com participação de carros alegóricos e efeitos cênicos. A dança, nessa época, era quase exclusivamente masculina, mas, nesse balé, começou a haver a participação de algumas damas da corte, formando o que se pode chamar de primeiro corpo de baile (grupo de bailarinos que realizam movimentos iguais) da história da dança. Iniciou-se, então, a formação de muitos desenhos geométricos e direções no espaço na movimentação da dança, lançando-se os fundamentos de uma nova forma de arte. (RENGEL E LANGENDONCK, 2006, p.7)

Em torno de todo movimento dos modos de produção, Eric Hobsbawm (2008), em A Era dos Extremos, no capítulo sobre a Revolução Cultural, nos aponta como a Revolução Industrial impõe mudanças nas relações sociais, a divisão da sociedade em classes; 
a chegada da maquinaria, portanto, se configurando no modo de produção capitalista. É neste período que vamos encontrar sistematizações da dança:

Carlo Blasis (1795-1878), italiano, grande estudioso da escultura e da anatomia, escreveu Treatise on the Art of Dancing (Tratado sobre a Arte da Dança), O balé romântico se desenvolve na França e se estende por toda a Europa... O balé modificou-se, em busca desse novo mundo de sonhos. Os passos não serviam mais unicamente para a evolução da ação, mas estavam carregados de um conteúdo emocional profundo. (RENGEL e LANGENDONCK, 2006, p.9)

A Dança no modo de produção Capitalista visa adequação as novas técnicas, tendo como seus balizadores François Delsarte, Emile Jacques Dalcroze, Rudolph Laban, categorizando o balé clássico em suas posturas e posições. No século XX, a dança moderna é tradicionalmente associada à estadunidense Isadora Duncan (1878-1927), mas, na realidade, ela nasce quase que simultaneamente em dois países: Estados Unidos, não somente com Isadora, mas também com Loïe Fuller (1862-1928) e Ruth St. Denis (1877-1968), e na Alemanha, com Rudolf Laban (1879-1958) e Mary Wigman (1886-1973).

Muitos modernos foram fiéis às estruturas formais estabelecidas pelo balé clássico, porém, buscando uma técnica de dança mais livre, ou seja, conquistando mais liberdade na elaboração dos movimentos. Eles se direcionavam de acordo com os acontecimentos sociais e políticos do mundo em transformação e às descobertas da arte de seu tempo.

Então, vejamos as possibilidades através da dança. 1) como arte: como uma possibilidade de conhecimento de si e do mundo a partir da experiência do fazer artístico; e 2) como linguagem social: como transmissão de sentimentos, saberes e hábitos; 3) como elemento da cultura corporal: cuja expressão é fundamentada na própria vida, ou seja, é reflexo das relações sociais em diferentes períodos históricos, portanto, pode refletir distintos sentidos e significados.

Portanto, apreendendo o conceito marxista sobre o trabalho, a dança é uma atividade que tem sua gênese no trabalho humano, com o sentido ontológico de formar o ser social. Esta atividade, que vai sendo sistematizada pela humanidade, chega aos nossos dias com características que lhe são próprias e que decorrem do modo de produção da vida em cada período histórico. A dança evidencia formas de expressão artística e pessoal. Estudar as danças nos possibilita conhecer várias culturas, porque as formas de dançar de um povo revelam muitas coisas sobre seu modo de vida.

Compreendo que a dança é uma das manifestações culturais da humanidade que está presente em toda a sua história. Ouve-se, por todos os lados: "dança é vida", "dança é mediação", "dança é um ritual". "Dançamos para nos comunicar", "para expressar nossos sentimentos", "para contar e recontar"... Por vezes identifico uma visão muito romântica de que "dança é tudo". É fato, porém, que a dança acompanha nossas vidas de diferentes formas, em diferentes épocas e com diferentes sentidos; podemos vê-la pelos diversos cantos do mundo. Atualmente, a dança está presente nas ruas, nas casas, nos espaços de espetáculos, nos estúdios, nas escolas, nas universidades, entre outros espaços (BRASILEIRO, 2010, p, 137). 
Dialogando com os autores acima, conceituamos dança como uma atividade vital do homem, ou seja, o trabalho, neste caso a produção da cultura que possibilita as diversas manifestações corporais, levando em consideração as relações sociais, sua relação com a natureza, em si e para si, das formas mais diversa de expressão do ser humano em seu desenvolvimento histórico, explorando os mais variados ritmos, movimentos e espaço.

\section{As principais atividades para o ensino da dança}

Na perspectiva do desenvolvimento humano Omnilateral, o Coletivo de Autores define o seguinte sobre a dança:

Na dança são determinantes as possibilidades expressivas de cada aluno, o que exige habilidades corporais que, necessariamente, se obtêm como treinamento/ Em certo sentido, esse é o aspecto mais complexo do ensino da dança na escola: a decisão de ensinar gestos e movimentos técnicos, prejudicando a expressão espontânea, ou de imprimir no aluno um determinado pensamento/sentido/intuitivo da dança para favorecer o surgimento da expressão espontânea, abandonando a formação técnica necessária à expressão certa. (COLETIVO DE AUTORES, 2009, p.81).

Ademais, não podemos negar na escola o conhecimento clássico da dança, suas técnicas e habilidades especificas. Assegurar nas escolas a dança e os outros conteúdos específicos produzidos culturalmente pela humanidade significa estar sintonizado com um projeto histórico que visa superar as contradições do modo de produção capitalista, que nega o acesso aos bens culturais, socialmente elaborados, para a maioria dos trabalhadores.

Superar obstáculos, conduzi-los a conhecer as limitações corporais para transpô-las, este é mais um sentido sobre o ensinar da dança na escola. Devemos possibilitar que os estudantes tenham acesso aos mais variados estilos e técnicas, não como imposição, mas, como fomento de conhecimento da cultura da humanidade. De acordo com Leontiev (2004, p.279) "o homem é um ser de natureza social, que tudo o que tem de humano nele provém da sua vida em sociedade, no seio da cultura criada pela humanidade".

E se tratando de Brasil, dimensionar este ensino inserindo os traços da cultura na dimensão das três matrizes de formação do povo brasileiro.

No livro Conformismo e Resistência, de Marilena Chauí (1986, p.24), a autora expõe que a cultura popular é outra cultura ao lado da dominante, a cultura das elites, ainda que para resistir a ela.

Em diálogo com a proposição de ensino da Educação Física Crítico Superadora, sistematizada pelo Coletivo de Autores (2009), estabelecemos como traços essenciais para o ensino dança: 1)Ritmo- este pode ser acelerado, lento, moderado e cadenciado; 2) 
Tempo- as variações rítmicas que se dão através compassos musicais; 3) Os movimentospodem ser cadenciados, balanceados e alongados, simétrico e assimétrico em relação ao espaço, em relação ao corpo, em relação ao grupo; 4) Sincronia coreográfica- segundo Laban (1978) é a variação do movimento, a forma de executá-lo e o tempo. Este se dá em três estágios: Unimoto (execução de movimentos iguais em tempos musicais iguais), sucessão (os movimentos podem ser iguais e diferentes, porém executados em tempos musicais sucessivos) e Canon ou Canone (os movimentos são diferentes executados no mesmo tempo musical); 5) Os níveis coreográficos do movimento- os níveis referem-se a altura em que um movimento pode ser realizado (nível alto: posição em pé, para cima (saltos); nível médio: movimento realizado com joelhos ou tronco flexionados; nível baixo: cócoras, ajoelhado, sentado e deitado); 6) Planos- Quando o movimento é realizado frontal, sagital ou horizontal; 7) direção- é a rota do movimento, este tem como orientação a saída pelo eixo central do corpo e 8) estética- A dança passa a ser compreendida pelo aprimoramento da organização deste conjunto de ações. A expressão através do movimento surge quando o ser humano encontra uma informação determinante que pode ser transmitida neste conjunto, e por ela descubra um assunto a ser conversado através do movimento.

Os estudos de Laban (1978) conceituam a articulação entre esses traços essenciais de coreologia, que é a forma de articular os movimentos, o ritmo, o espaço, o corpo em todas suas expansões e dimensões aos diversos estilos de dança.

Porém, para que estes fundamentos tenham sentido na escola, precisamos problematiza-los, expressar esses traços essenciais a partir de outro fundamento que vamos expor a seguir: 9) problematização- esta incide em articular as diversas formas de dança com o contexto político, histórico e social dos estudantes. A problematização está vinculada ao mundo do trabalho, ao mundo da escola, o estado afetivo, as questões relativas às interseccionalidades (classe, raça e gênero), os seres e fenômenos do mundo animal, vegetal e mineral segundo o Coletivo de Autores (2009).

Outro ponto fundamental é a classificação da dança. Assim, devemos levar em consideração sua gênese e a historicidade, que apresentam em seu desenvolvimento as danças primitivas, danças milenares, dança moderna, dança neo clássica, clássica, danças contemporaneas danças de salão, danças populares e acrescentamos em acordo com Marques (1997) as danças regionais, étnicas, nacionais e internacionais.

\section{A dança: organização e sistematização do conhecimento}

Diante do esforço em selecionar os conteúdos (o que ensinar?), vamos à organização deste conhecimento, à proposta de trabalho do trato com o conhecimento da dança, através da proposição crítico superadora (metodologia de ensino da EF). Enquanto 
organização nos Ciclos de Escolarização, como já explicitamos os conceitos nos ciclos deste estudo, vamos primar que o professor considere que os conteúdos são simultâneos, pois eles podem ser sistematizados em todos os ciclos, desde que levem em consideração o estágio de desenvolvimento dos estudantes. Por exemplo: a forma de trabalhar pedagogicamente o conteúdo ritmo e movimento no primeiro ciclo de escolarização não será a mesma forma a ser trabalhada no terceiro ciclo de escolarização.

Segundo Martins (2013), o ensino é a mediação entre a aprendizagem e o desenvolvimento psíquico. Isso prova que a seleção dos conteúdos e a forma organizativa da aprendizagem não são fatores secundários. A autora se orienta pelos estudos de Vigotsky à luz da psicologia histórico cultural. Este estudo aponta que:

\begin{abstract}
A instrução desponta como condição para o desenvolvimento, ou seja, entre esses processos se instala uma relação de condicionabilidade recíproca, explicável à luz do preceito lógico dialético da dinâmica entre " quantidade e qualidade", ou seja, a "quantidade" de aprendizagens promovidas pelo ensino qualifica o desenvolvimento, à mesma medida que a "quantidade" de desenvolvimento qualifica as possibilidades para o ensino. (MARTINS, 2013, p. 278)
\end{abstract}

Tendo o professor de EF como sujeito mediador no processo de transmissão/assimilação do conhecimento, a escola deve determinar, a partir do seu planejamento, os conteúdos relevantes em defesa de ensinar conhecimentos científicos e não cotidianos, que tendem a estabilizar o desenvolvimento do estudante. Bem, se o aluno vai para escola ter acesso ao que já sabe, para que serve a escola? A escola, assim como o professor não deve reproduzir o conhecimento tácito.

Saviani (2008) diz que o planejamento é intencional, que forma e conteúdo são dialéticos, que a ações didáticas e as sistematizações dos saberes elaborados historicamente pela humanidade é que diferenciam qualitativamente a educação da escola da educação informal. Portanto a relevância dos conteúdos é um dado nuclear da educação escolar.

Assim, na proposição crítico superadora a organização simultânea dos conteúdos da dança objetiva as possibilidades de requalificar as funções psíquicas, desde a infância até a fase adulta, de acordo com os ciclos de escolarização.

\title{
Sistematização do trato com o conhecimento da dança na escola
}

Este é o momento em que vamos evidenciar a prática pedagógica, ou seja, como ensinar? O que significa, na perspectiva do ensino, que objetive a formação omnilateral, contra hegemônica ao sistema de educação vigente no Brasil, e que seja uma prática revolucionária.

Esta prática, à luz da Pedagogia Histórico Crítica (PHC), tem o método dialético como referência para a organização da prática pedagógica, e possibilita estruturar o 
trabalho educativo, oferecendo ao estudante as condições de apropriação de toda cultura produzida pelos indivíduos que lhe antecederam (SAVIANI, 2008).

O autor expõe sua proposição, partindo prática social e voltando a ela. Ele estabeleceu a partir da prática social um sistema dos princípios da Pedagogia Histórico Crítica: Prática social inicial; Problematização; Instrumentalização; Catarse e Prática social final.

Prática Social inicial Fundamentado em Marx, este princípio não se relaciona apenas às noções particulares que um estudante tem sobre ele. A ideia de partir do conhecimento "cotidiano" se remete às ideias de ordem do concreto difuso; este conhecimento, segundo Saviani, deve ser analisado com radicalidade, rigorosidade e globalidade. Marsiglia (2013, p.224) diz que:

Como ponto de partida da prática pedagógica, ela é diferentemente compreendida pelos educandos e pelo educador, pois enquanto os primeiros têm uma noção sincrética, o professor tem uma síntese precária, isto é, ele já se apropriou de níveis mais elaborados que compõe aquele conteúdo; expressa um conhecimento de essência, porque abarca as múltiplas determinações do fenômeno.

A autora conceitua síntese precária, porque o conhecimento não é absoluto. No caso do professor, sempre pode-se acrescentar mais elementos explicativos. O professor em relação ao educando precisa objetivar o conhecimento, o que significa objetivar-se a partir do real concreto da forma mais enriquecedora. Para tal, orientando-nos pelo autor da proposição pedagógica, devemos problematizar a realidade. É a prática social inicial que aponta esta necessidade. A prática social inicial no trato com o conhecimento da dança acontece quando se faz reconhecimento e levantamento da discussão sobre o conhecimento prévio dos alunos, e até que ponto se apropriam e reconhecem as danças em suas comunidades e as danças desenvolvidas historicamente como patrimônio cultural da humanidade. Problematização - Saviani (2004) salienta que uma questão por si não se caracteriza como um problema, pois este é caracterizado quando se necessita conhecer a resposta a uma questão.Então, a problematização se dá com o atendimento das necessidades postas pela prática social. Assim,

[...] devemos sublinhar que assim como a prática social não é particular, também não o são os problemas. A ideia de problema não se resume aquilo que um grupo de alunos está interessado em saber e por isso se revela uma necessidade. Para a pedagogia histórico crítica, o professor é quem dirige o processo educativo porque, como mais desenvolvido, tem condições de criar motivos da aprendizagem, ainda que eles não estejam ao alcance da compreensão imediata dos alunos. (MARSIGLIA,2013, p.226)

Desta forma, com o grau de apropriação do conhecimento, estabelecemos a realidade e as possibilidades de ensino sobre a dança. A) De acordo com o diagnóstico, tratar o conhecimento da dança no currículo da escola de forma científica; B) questionar o trabalho com a dança diante de tanta exacerbação da sensualidade feminina nas 
comunidades, questões de gênero, ou seja, articular os problemas históricos, políticos e sociais ao trato; C) quais conteúdos sobre a dança como patrimônio histórico da humanidade contribuem para elevação do padrão cultural dos estudantes a fim de propiciar a emancipação humana? D) diante de uma unidade escolar sem estrutura física, que estratégias estabelecer para que as ações pedagógicas possam se materializar? Estes são apenas alguns exemplos para problematizar.

Portanto, a partir da problematização estabelecem-se os conteúdos necessários a conhecer; estes conteúdos selecionados efetivam-se quando são humanizantes e dão condição a saltos qualitativos no padrão cultural dos estudantes, propiciando a emancipação humana. Instrumentalização é o momento da prática pedagógica em que ensinamos os elementos culturais que precisam ser assimilados pelos estudantes e desenvolve-se através do ensino de tudo que é historicamente desenvolvido pelo homem. Neste contexto, desenvolvemos as aulas e seminários sobre as danças - estabelecendo o contexto histórico, aproximando-as da realidade dos estudantes, com oficinas dos vários estilos Trata-se do ensino de tudo que é clássico e que ao mesmo tempo é moderno, representando a atualidade de um desenvolvimento científico.

Para a pedagogia histórico crítica, isso é impensável, uma vez que o desenvolvimento não é algo endógeno, e sim social e histórico. Se o aluno escreve errado, seu texto é pobre de vocabulário e conceitos, cabe ao professor reconhecer as razões desses problemas, selecionar as ferramentas mais adequadas para sua mediação (ensino!) e assim instrumentalizar o educando com o que é necessário para superação dos limites que se apresentam. (MARSIGLIA, 2013, p.234)

Catarse é quando o educando se apropria e incorpora os instrumentos culturais e consegue torná-los elementos ativos de transformação social (SAVIANI, 2008), este atribui neste passo o método dialético, onde, a partir das mediações, o estudante ascende o real concreto, fazendo novas elaborações do que foi apreendido. O objetivo internalizado se transforma em subjetivo. Então, possibilitamos que os estudantes elaborem composições coreográficas com autoria, fundamentados e instrumentalizados. Podemos propiciar a organização de eventos, divulgação, cenário, apresentações. As generalizações partem do desenvolvimento dos estudantes e a instrumentalização é possibilitada pelo ciclo de escolarização.

E agora, o retorno à prática social (final) significa que o processo de uma prática pedagógica histórico crítica contribui para o desenvolvimento psíquico dos estudantes. Este é a avaliação da apreensão dos processos significativos no trato do conhecimento da dança e que avanços ocorreram. De acordo com Saviani (2012), a prática social, ao final, é e não é a mesma. Isto se dá porque, se constatamos que os estudantes evoluíram qualitativamente ao elaborar sínteses quanto ao conhecimento cientifico, a prática social foi alterada; caso não, precisaremos de novos instrumentos para alterar o processo de transmissão/assimilação do conhecimento. 
Segundo Luiz Carlos de Freitas (1985, p.225), "o eixo central do processo didático e da organização do trabalho pedagógico é dado pelo par dialético objetivos/avaliação". O profissional de Educação Física, ao trabalhar os conteúdos relevantes no âmbito da cultura corporal, deve problematizar, diagnosticar a realidade e saber onde quer chegar, possibilitando saltos qualitativos no desenvolvimento a ser propiciado aos estudantes.

\section{Considerações finais}

Esta proposição sobre o trato com o conhecimento da dança na escola aponta como uma das possibilidades alterar as condições em que se encontra a escola na sociedade brasileira, uma escola em que predomina a divisão do saber. Vislumbramos uma prática pedagógica que traga contribuições específicas para desenvolver qualitativamente a classe trabalhadora.

O curso de formação de professores elaborado pelo coletivo, ou seja, Grupo de estudos Lepel/UFBA, defende a direção de uma formação humana, que se expressa na pedagogia explicitada pela teoria da educação visando à transformação da sociedade. Levando-se em consideração que a pedagogia histórico-crítica possui como pressuposto o materialismo histórico, que busca compreender a história a partir do desenvolvimento material, da determinação das condições materiais da existência humana. Desta forma, o Trato com o conhecimento da dança deve dialogar com tais pressupostos teóricos metodológicos e estabelecer nexos para o enfrentamento das problemáticas sociais na escola.

Para tal, saímos em defesa dos profissionais da educação, da escola básica, enfim da classe trabalhadora, por uma educação de qualidade que possibilite a revolução, a transformação da sociedade pautada no capital.

Recebido em 17/10/2016 e aprovado em 07/04/2017

\section{Referências}

BRASIL. Constituição da República Federativa do Brasil de 1988.

. Lei de Diretrizes e Bases da Educação Brasileira 9394/96.

BRASILEIRO, Lívia Tenório. O conteúdo "dança” em aulas de educação física: temos o que ensinar?

Revista Pensar a Prática, Goiânia, v. 6, n. 1, p. 45-58, 2003.

CHAUI, Marilena. Conformismo e resistência, aspectos da cultura popular no Brasil. São Paulo: Editora Brasiliense, 1986. 
CLIMACO, Josiane. C. A produção do conhecimento do subprojeto Pibid Educação Fisica: realidade e possibilidades no trato com conhecimento na formação inicial de professores. 146f. Dissertação (Mestrado). Faculdade de Educação, Universidade Federal da Bahia: Salvador, 2016.

COLETIVO DE AUTORES. Metodologia do ensino da Educação Física. São Paulo: Cortez, 2009.

ESCOBAR, M. O. Transformação da didática: construção da teoria pedagógica como categorias da prática pedagógica. Tese de Doutorado, Faculdade de Educação, Universidade Estadual de Campinas: Campinas, 1997.

FREITAS, L. C. Crítica da organização do trabalho pedagógico e da didática. 5 ed. Campinas: Papirus, 2011.

GAMA, C. N. Princípios curriculares à luz da Pedagogia histórico-crítica: as contribuições da obra de Dermeval Saviani. 2015. 232 f. Tese de Doutorado (Doutorado em Educação) - Universidade Federal da Bahia, Salvador, 2015.

HOBSBAWM, Eric. A era dos extremos, o breve século XX 1914-1991 Tradução: Marcos Santarrita. Revisão técnica: Maria Célia Paoli. 2 edição, 9a reimpressão. São Paulo: Companhia das Letras, 1995.

LABAN, R. Domínio do movimento. São Paulo: Summus, 1978.

LANGENDONCK, Rosana van. História da dança. 2006 Disponível em: http://culturaecurriculo. fde.sp.gov.br/administracao/Anexos/Documentos/420091014164533Linha\%20do\%20Tempo\%20-\%20 Historia\%20da\%20Danca.pdf Acesso em 27 de jan. 2014.

LEONTIEV, Alexis. O desenvolvimento do psiquismo. 2. ed. São Paulo: Centauro, 2004.

KOSIK, K. Dialética do concreto. 7. ed. Rio de Janeiro: Paz e Terra, 2002.

MANACORDA, Mario Alighiero. Marx e a pedagogia moderna. ª ed. São Paulo: Alínea, 2010.

MARQUES, I.A. Dançando na escola. São Paulo: Cortez, 2003.

MARSÍGLIA, A. C. G. (org.). Pedagogia histórico-crítica: 30 anos. Campinas: Autores Associados, 2011.

. (org.). Infância e pedagogia histórico-crítica. Campinas, SP: Autores Associados, 2013.

MARTINS, L. M. O desenvolvimento do psiquismo e a educação escolar: contribuições à luz da psicologia histórico-cultural e da pedagogia histórico-crítica. Campinas, SP: Autores Associados, 2013.

MARX, K. Contribuição à crítica da economia política. Tradução e introdução Florestan Fernandes. 2.ed. São Paulo: Editora Expressão Popular, 2008.

O capital: crítica da economia política. 15ed. Rio de Janeiro: Bertrand Brasil, 1996. Livro 1, v. I.

Trabalho estranhado e propriedade privada. In: Manuscritos econômico-filosóficos. São Paulo: Boitempo, 2004.

MARX,Karl,ENGELS,Friedrich. Manifesto do partido comunista.1ª edição, São Paulo: Editora Expressão Popular, 2008.

. A Ideologia Alemã, 1ªedição, São Paulo: Editora Expressão Popular, 2009.

MELO, Adriana Almeida Sales de. A Mundialização da educação. Consolidação do projeto neoliberal no Brasil e na Venezuela. Maceió: Edufal, 2004. 
PORTINARI, Maribel. História da dança. Rio de Janeiro: Nova Fronteira, 1989

RENGEL, Lenira e LANGENDONCK, Rosana. Pequena viagem pelo mundo da dança. São Paulo: Moderna, 2006.

Projetos de Pesquisa, fundamentos lógicos: a dialética entre pergunta e resposta. Chapecó: Argos. 2013. 159 p.

SAVIANI, D. Educação: do senso comum à consciência filosófica. 15 ed. Campinas, SP: Autores Associados, 2004.

História das ideias pedagógicas no Brasil. Campinas, SP: Autores Associados, 2007.

Pedagogia histórico-crítica: primeiras aproximações. 10. ed. rev. Campinas: Autores Associados, 2008.

SAVIANI, D. \& DUARTE, N. (orgs.). Pedagogia histórico-crítica e luta de classes na educação escolar. Campinas, SP: Autores Associados, 2012

SILVA, William Jose Lordelo. Crítica à Teoria Pedagógica da Educação Física: para além da formação unilateral. 112 f. 2011. Dissertação (Mestrado) - Faculdade de Educação, Universidade Federal da Bahia, Salvador, 2011.

TAFFAREL, C. N. Z. Formação do profissional da educação: o processo de trabalho pedagógico e o trato com o conhecimento no curso de educação física. Tese de Doutorado, Faculdade de Educação, Universidade Estadual de Campinas. Campinas, 1993.

TAFFAREL, C. N. Z.; SANTOS JÚNIOR, C. de L.; COLAVOLPE, C. R. Trabalho pedagógico e a formação de professores/militantes culturais: construindo políticas para a educação física, esporte e lazer. Salvador: EDUFBA, 2009.

TAFFAREL, Celi N. Z.; RODRIGUES, Raquel F.; MORSCHBACHER, Márcia. A perspectiva da formação docente: Analisando reinvindicações históricas e propondo táticas superadoras. Universidade e Sociedade, Brasília, ano XXII, n. 51, p. 60-73, mar. 2013.

ZANELLA, A.V. Considerações à luz da psicologia histórico-cultural. Psicologia em Estudo. Maringá, v. 9, n. 1.2004. 